\title{
ERCP for biliary stones in the elderly: should we stop ducking the cholecystectomy?
}

Author

Institution
Daniel S. Strand

Division of Gastroenterology and Hepatology, University of Virginia, Charlottesville, VA, United States
Bibliography

DOI http://dx.doi.org/

10.1055/s-0041-107896

Published online: 11.1.2016

Endoscopy International Open

2016; 04: E91-E92

(c) Georg Thieme Verlag KG

Stuttgart $\cdot$ New York

E-ISSN 2196-9736

\section{Corresponding author}

Daniel Strand, MD. Assistant

Professor of Medicine

Division of Gastroenterology

and Hepatology

Box 800708

University of Virginia Health

System

Charlottesville, VA 22908

USA

Phone: 434-297-7208

Fax: 434-244-7590

dss7a@virginia.edu
Since endoscopic retrograde cholangiopancreatography (ERCP) was first described in 1968, the procedure has become indispensable in management of biliary tract stones [1]. Endoscopic biliary sphincterotomy, with or without papillary balloon dilation (EPBD), is considered to be highly effective for the removal of all but the most challenging stones. Even in cases where a more complex intervention is required, ERCP provides the platform for directed stone remediation via mechanical, laser, or electrohydraulic lithotripsy [2]. In spite of its undeniable efficacy and central role in management of choledocholithiasis, ERCP carries a well-recognized profile of inherent risks which may occur in up to $10 \%$ of patients who undergo the procedure [3]. In view of that, considerable effort has been expended in identifying and stratifying patients and situations that contribute to increased risk. Particular attention is frequently given to short-term problems such as post-ERCP pancreatitis (PEP) [4].

As the life expectancy and proportion of elderly patients increases throughout much of the developed world [5], we can reasonably expect that the number of octogenarians and nonagenarians who undergo ERCP will increase accordingly. Indeed, an intramural survey of ERCP volume at our institution over the last 12 months demonstrated that out of well over 1000 total cases, more than $40 \%$ of the procedures were performed on patients over age 65 and nearly $10 \%$ were done on individuals in their $80 \mathrm{~s}$ and $90 \mathrm{~s}$. Given the reasonable expectation that ERCP in the elderly will become a more common exercise among interventional gastroenterologists, a comprehensive understanding of the risks and challenges of this patient population is critical.

In this issue of Endoscopy International Open, Kenamori et al [6] present a large, single-center cohort study examining both the short- and longterm outcomes of patients who underwent therapeutic ERCP for choledocholithiasis between 1982 and 2011.Patients included in the study were stratified by age and were classified as either young ( 960 patients $<80$ years) or old ( $250 \mathrm{pa}$ tients $\geq 80$ years) for subsequent analysis. While it has been previously asserted that the shortterm risks of ERCP in older adults are generally acceptable [7], there is a growing body of evidence regarding specific differences in this patient population. A systematic review published in the current journal by Day et al [8] suggested that patients over age 65 have a nearly $70 \%$ overall reduction in post-ERCP pancreatitis when compared to younger cohorts. This is consistent with the experience reported by Kenamori et al, and when taken together with contemporary work, seems to support the notion of a "dose-dependent" protective effect of advancing age on PEP [9-11]. Kenamori et al also suggest similar outcomes between age groups when it comes to other short-term complications such as bleeding, periprocedural infection (cholecystitis or cholangitis) and perforation. Despite the overall congruence, older patients did carry an increased risk of cardiopulmonary complications. While consistent with Day et al [8], this observation may have more to do with the medical comorbidities carried by elderly patients rather than with age alone $[12,13]$.

While most studies to date have focused on the short-term complications of ERCP in the elderly, there is relatively little published data examining long-term outcomes in these patients. What data we do have suggest that complete treatment of biliary lithiasis may affect the overall survival of the elderly who require ERCP [14]. While the authors of Kenamori et al acknowledge that the broad time course of their study may have introduced unintended bias, it also permitted extended follow-up (a mean of 1278 days in the older cohort) in a fairly large number of patients. Perhaps the most interesting observation made by the authors is the increased likelihood $(20.4 \% \mathrm{v}$. 
$13.1 \%)$ of late pancreaticobiliary complications in older patients, and the shorter mean time until their occurrence (464.3 v. 860.4 days) compared to their younger comparators. This difference was driven by both the recurrence of bile duct stones after clearance and the development of subsequent cholangitis. Both of these events occurred more commonly among older patients, long after the initial successful ERCP. The common thread in both a univariate (6-fold) and multivariate (4-fold) analysis was the presence of an in situ gallbladder with additional stones.

The current guidelines published by the Society of American Gastrointestinal and Endoscopic Surgeons suggest that laparoscopic cholecystectomy is indicated for any patient who has suffered a complication of cholelithiasis [15]. Despite this definite recommendation, adherence to these guidelines among older patients is low [16]. This occurs despite the observation that laparoscopic cholecystectomy is generally safe, even in extremely elderly patients $[17,18]$. Surgeons often decide to pursue an intervention (or not) on the basis of a number of situational factors: patient autonomy, social support, medical comorbidities, higher American Society of Anesthesiologists (ASA) status, diminished functional capacity, and the nature of the acute illness. As with ourselves, there is likely a human tendency to make the short-term issues weightier than those of the long-term.

It is clear that elderly patients require special consideration when it comes to any intervention, whether it be ERCP or laparoscopic cholecystectomy. Age alone, however, does not preclude either in patients who would clearly otherwise benefit $[8,16]$. While there is ample room to determine what pre- and post-procedure strategies might favor the proximate safety of ERCP in this setting, it is significant that the largest long-term issue uncovered by Kenamori et al may be one of "unfinished business." Many of the patients at highest risk for subsequent biliary complications had already tolerated ERCP and its attendant tribulations successfully, but either declined or were not offered interval cholecystectomy. This pattern, congruent with other experiences [16], suggest a willingness to go "part of the way" to ERCP but not "all of the way" to cholecystectomy. While this strategy favors short-term safety, we may well be inviting a likely downstream complication in a patient who will be older (but perhaps no wiser) when it occurs. Therefore, if we are "in for a penny" when an elderly patient arrives with choledocholithiasis, should we invariably be "in for a pound"?

ERCP and laparoscopic cholecystectomy are similar, but they are clearly not the same. No blanket recommendation can be made to suggest that tolerating an ERCP for duct clearance will portend a good outcome at cholecystectomy. Despite this fact, the data provided by Kenamori et al are helpful: they solidify the shortterm safety of ERCP in the elderly and serve to help us better edu- cate our patients about downstream problems. The data also raise several questions regarding cholecystectomy, and continue to focus attention on the ongoing need for study in this vulnerable and growing group of patients.

\section{Competing interests: None}

\section{References}

1 McCune WS, Shorb PE, Moscovitz H. Endoscopic cannulation of the ampulla of vater: a preliminary report. Ann Surg 1968; 167: 752 - 756

2 Committee ASoP Maple JT, Ikenberry SO et al. The role of endoscopy in the management of choledocholithiasis. Gastrointest Endosc 2011; 74: $731-744$

3 Committee ASoP Anderson MA, Fisher $L$ et al. Complications of ERCP. Gastrointest Endosc 2012; 75: 467-473

4 Freeman ML. Pancreatic stents for prevention of post-endoscopic retrograde cholangiopancreatography pancreatitis. Clin Gastroenterol Hepatol 2007; 5: 1354-1365

5 World Health Organization. World health statistics 2013. Geneva: World Health Organization; 2013

6 Kanamori A, Kiriyama S, Tanikawa $M$ et al. Long and short-term outcomes of ERCP for bile duct stones in patients over 80 years old compared to younger patients: a propensity score analysis. Endoscopy International Open 2016

7 Travis AC, Pievsky D, Saltzman JR. Endoscopy in the elderly. Am J Gastroenterol 2012; 107: 1495 - 501; quiz 1494, 1502

8 Day LW, Lin L, Somsouk M. Adverse events in older patients undergoing ERCP: a systematic review and meta-analysis. Endosc Int Open 2014; 2: E28-E36

9 Behlul B, Ayfer S, Sezgin V et al. Safety of endoscopic retrograde cholangiopancreatography in patients 80 years of age and older. Prz Gastroenterol 2014; 9: 227-231

10 Yun DY, Han J, Oh JS et al. Is endoscopic retrograde cholangiopancreatography safe in patients 90 years of age and older? Gut Liver 2014; 8: $552-556$

11 Maitin-Casalis N, Neeman T, Thomson A. The protective effect of advanced age on post-ERCP pancreatitis and unplanned hospitalisation. Intern Med J 2015; 45: 1020-1025

12 Partridge JS, Harari D, Martin FC et al. The impact of pre-operative comprehensive geriatric assessment on postoperative outcomes in older patients undergoing scheduled surgery: a systematic review. Anaesthesia 2014; 69: 8-16

13 Fisher L, Fisher A, Thomson A. Cardiopulmonary complications of ERCP in older patients. Gastrointest Endosc 2006; 63: 948-55

$14 \mathrm{Hu}$ L, Sun X, Hao J et al. Long-term follow-up of therapeutic ERCP in 78 patients aged 90 years or older. Sci Rep 2014; 4: 4918

15 Overby DW, Apelgren KN, Richardson W et al. SAGES guidelines for the clinical application of laparoscopic biliary tract surgery. Surg Endosc 2010; 24: $2368-2386$

16 Trust MD, Sheffield KM, Boyd CA et al. Gallstone pancreatitis in older patients: Are we operating enough? Surgery 2011; 150: 515-525

17 Marcari RS, Lupinacci RM, Nadal LR et al. Outcomes of laparoscopic cholecystectomy in octogenarians. JSLS 2012; 16: 271 -275

18 Lee SI, Na BG, Yoo YS et al. Clinical outcome for laparoscopic cholecystectomy in extremely elderly patients. Ann Surg Treat Res 2015; 88: $145-151$ 